\title{
$\mathrm{Ad}-\mathrm{hoc}$ 네트워크 환경에서 DSDV 라우팅 알고리즘을 이용한 위치 정보 시스템 및 사용자 맵핑 시스템의 설계 및 구현
}

곽 종 욱*

\section{Design and Implementation of Location Information System and User Mapping System using DSDV Routing Algorithm in Ad-hoc Network Environment}

Jong Wook Kwak*

\section{요 약}

본 논문에서는 다수의 이동 가능한 관리 대상을 소수의 관리자가 효율적으로 관리하기 위하여 $\mathrm{Ad}-\mathrm{hoc}$ 네트워크 환경에서 DSDV(Destination Sequenced Distance Vector) 라우팅 알고리즘을 활용하는 위치 정보 시스템을 구현하며, 또한 이를 효율적으로 제어하기 위한 사용자 맵핑 시스템을 설계하고 구현한다. 제안된 시스템의 소프트 웨어 부분에서는 다수의 위치 정보 노드들이 Ad-hoc 네트워크 환경에서 DSDV 라우팅 알고리즘으로 네트워크를 구축하고, 구축된 네트워크에서 하나 이상의 위치 정보 노드가 사라지면 진동과 같은 경고 시스템을 활성화한다. 하 드웨어로 구현된 사용자 맵핑 시스템은 사용자 위치 정보 노드(u_LIN, User Location Information Node)라 명 명된 장치들이 네트워크를 구축한 뒤, 그 네트워크에서 하나 이상의 u_LIN이 사라지면 경고 시스템을 활성화 하여 사라진 u_LIN을 찾도록 도와주는 시스템이다. 본 시스템의 설계로 구현된 프로토타입으로 성능 평가를 수행한 결 과, 사용자 위치 정보 노드 간 $1: 1$ 통신을 직선거리에서 수행하였을 때, 약 $250 \mathrm{~m}$ 까지 통신이 가능하였으며, $1: \mathrm{N}$ 통신의 경우 약 $100 \mathrm{~m}$ 이내의 거리에서 정상적으로 통신이 이루어지는 것을 확인하였다. 본 논문에서 구현된 시스 템은 유치원 아동 관리 시스템, 놀이공원 미아 방지 시스템, 관광객 관리 시스템 등 여러 시스템에 매우 유연하게 적용이 가능하여 그 활용도가 높을 것으로 예상된다.

- Keywords : Ad-hoc 네트워크, DSDV 라우팅 알고리즘, 위치 정보 시스템, 사용자 맵핑 시스템, 안드 로이드 어플리케이션

-제 1 저자 : 곽종욱 • 교신저자 : 곽종욱

•투고일 : 2013. 12. 12, 심사일 : 2014. 1. 11, 게재확정일 : 2014. 2. 20

* 영남대학교 컴퓨터공학과(Dept. of Computer Engineering, Yeungnam University) 


\begin{abstract}
In this paper, we design and implement location information system and user mapping system using DSDV(Destination Sequenced Distance Vector) routing algorithm in ad-hoc network environment to efficient manage a number of mobile devices. The software part in proposed system construct ad-hoc network using DSDV routing algorithm and it activate alarm system, such as vibration, when one of devices disappears in the network. The hardware system, called u_LIN (User Location Information Node) construct ad-hoc network and it helps to find a disappeared device by using warning system. When we evaluate the performance of our prototype system, we have checked a correct operation, within the range of $250 \mathrm{~m}$ in case of $1: 1$ communication and within the range of $100 \mathrm{~m}$ in case of $1: \mathrm{N}$ communication. The implemented system in this paper is highly expected to flexibly use in juvenile protection system, stray-child protection system, tourist guide system and so on.
\end{abstract}

- Keywords : ad-hoc network, DSDV routing algorithm, location information system, user mapping system, android application

\section{I. 서 론}

무선 네트워크의 기술 중 하나인 Ad-hoc 네트워크는 기지 국이나 AP(Access Point) 없이 무선으로 통신이 가능한 노 드들끼리 서로 정보를 주고받는 네트워크 구조로서, 최근 관 련 연구들이 활발하게 진행되고 있다. 이에 본 논문에서는 $\mathrm{Ad}-\mathrm{hoc}$ 네트워크 환경을 활용하는 사용자 위치 정보 시스템 을 구현한다. 이는 소수의 관리자가 다수의 이동 가능한 대상 을 제어하는 방식에 대한 주된 해결책이다. 즉 실제 유치원 관리 시스템이나 미아방지 시스템과 같이, 관리자가 관리 대 상을 시야에 두고 확인하면서 이탈하지 않도록 하는 상황은 지극히 제한적이며, 여러 돌발 상황이 발생할 수 있다.

이와 같은 상황에 대처하기 위해 본 논문에서는 다수의 관 리 대상을 소수의 관리자가 효율적으로 관리할 수 있도록, $\mathrm{Ad}-\mathrm{hoc}$ 네트워크를 이용하여 다수의 사용자 위치 정보 노드 들이 네트워크를 구성하고 위치 정보를 안드로이드 단말을 통 하여 확인하도록 한다. 또한 하나 이상의 사용자 위치 정보 노드가 기 구축된 네트워크에서 사라지면 진동이나 알람과 같
은 경고 시스템을 활성화시켜 사라진 사용자 정보 노드의 위 치 파악에 도움을 주는 기능을 제공한다.

본 논문에서 개발되는 안드로이드 기반 소프트웨어는 이동 성이 보장되는 Ad-hoc 네트워크를 이용하여 다수의 사용자 위치 정보 노드들이 네트워크를 구성하고, 해당 위치를 안드 로이드 환경을 통해 확인 가능하게 한다. 이를 바탕으로 하나 이상의 사용자 위치 정보 노드가 네트워크상에서 사라지면 해 당 사용자 위치 정보 노드를 찾도록 도와주는 사용자 맵핑 시 스템을 하드웨어적으로 구현한다. 또한 개발되는 위치 정보 시스템은 안드로이드 환경에서 시각적으로 노드들의 위치를 확인시켜 주어 관리 대상에 대한 관리를 도와준다. 본 논문에 서 구현된 시스템은 유치원 아동 관리 시스템, 놀이공원 미아 방지 시스템, 관광객 관리 시스템 등 여러 시스템에 매우 유 연하게 적용이 가능하여, 그 활용도가 높을 것으로 예상된다.

이하 본 논문의 구성은 다음과 같다. 2 장에서는 본 논문의 관련연구 및 배경지식에 대해 알아보고, 3장에서는 전체 시스 템 구성과 위치 정보 시스템의 구현 방법 및 구성 그리고 동 작과정에 대해 설명하며, 사용자 맵핑 시스템의 하드웨어로의 설계 및 구현에 대해 소개한다. 아울러, 4 장에서는 개발 및 
성능평가 환경을 소개하며 본 논문에서 제안한 시스템의 성능 에 대해 평가하고 분석한다. 마지막으로 5장에서는 본 논문에 서 구현한 시스템의 결론에 대해서 논의한다.

\section{II. 배경 지식 및 관련 연구}

\section{1. 무선 네트워크}

무선 네트워크(Wireless Network)란, 무선 전파를 이용 하는 통신 네트워크를 통칭하는 말이다. 신호를 전하는 케이 블 대신 무선 전파를 이용하는 통신 네트워크를 통틀어 무선 네트워크라고 한다. 주로 $\mathrm{PC}$ 나 $\mathrm{PDA}$ 단말기의 인터넷 접속 에 이용되는 경우가 많으며, 무선 인터넷 규약에 의해 사용하 는 것과 무선 랜(LAN)을 사용하는 방법이 대표적이다. 이러 한 무선 네트워크는 그림 1 에서와 같이 두 가지 종류로 분류 할 수 있다. 기지국이나 $\mathrm{AP}$ 를 중심으로 구성되는 인프라가 있는 Infrastructure 네트워크와 노드들로 구성된 인프라가 없는 $\mathrm{Ad}-\mathrm{hoc}$ 네트워크로 분류할 수 있다[1][2].

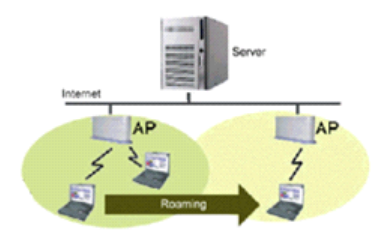

(a) Infrastructure 네트워크

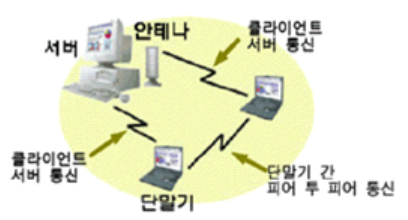

(b) Ad-hoc 네트워크

그림 1. 무선 네트워크

Fig. 1. Wireless Network

\section{Infrastructure 네트워크}

Infrastructure 네트워크는 망의 종단 부분이 무선으로 유선 네트워크와 연결되어 있어, 이를 Last Hop Network 라 한다. 기존에 설치된 인프라를 통해서만 데이터의 송수신 이 이루어지는 구조로 현재 많이 접하고 있는 이동 전화망이 나 무선 LAN 등을 대표적인 예로 들 수 있다. 인프라가 있는
네트워크는 기존 인프라를 통해서만 통신이 가능하기 때문에, 지진과 같은 재해나 테러 혹은 전쟁과 같은 상황에서 기지국 이나 $\mathrm{AP}$ 의 고장, 유선 단절과 같은 상황 발생 시 원활한 통신 을 수행할 수 없다는 단점이 있다.

\section{Ad-hoc 네트워크}

$\mathrm{Ad}-\mathrm{hoc}$ 네트워크는 중앙 집중화된 관리가 지원되지 않는 환경에서 이동성 지원 기반 시설의 도움 없이 임시로 네트워 크를 구성하는 이동 호스트와 무선 인터페이스의 집합이다 〔3]. 이러한 네트워크 구조에서 각 이동 호스트는 단말 호스 트이면서 또한 라우터로 동작하여 패킷을 다른 이동 호스트로 전달한다. 이 때, 이동성 지원 기술은 위치 정보가 서로 다른 하드웨어 특성 영역 혹은 서로 다른 이동 통신망 사이에서 단 말의 이동을 추적하고, 필요하다면 네트워크 구성 요소 사이 에 상호 전달하는데 소요되는 방법론을 통칭한다. Ad-hoc 네 트워크는 기존 인프라가 필요하지 않기 때문에 임시 구성용 네트워크나 재난 지역과 전쟁터와 같은 기반 시설이 없는 환 경에서 적용 가능하도록 주로 군사용 망에 중점을 두어 연구 개발 되었으나, 최근에는 원거리 네트워크뿐만 아니라 근거리 로컬 네트워크에서도 상업적으로 주목받기 시작했다[4][5].

\section{4. 위치 정보 시스템}

위치 정보 시스템을 구현하기 위한 시도가 통신 기술의 발 달과 더불어 최근 들어 활발히 지속되고 있다[6][7]. 이들은 특히 GPS 정보를 바탕으로 실내 혹은 실외 환경에서 $\mathrm{Wi}-\mathrm{Fi}$ 환경 등 다양한 네트워크 환경을 활용하여 구현되었다. 하지 만 기존의 연구는 통신 거리의 제약, 실내 공간으로서의 제약, 혹은 특정 네트워크 기반이라는 제약 조건을 가지는 경우가 많았다.

이와 관련하여 본 연구에서 제안되는 위치 정보 시스템은 기존 네트워크 인프라가 필요 없는 ad-hoc 네트워크를 활용 한다는 점과 안드로이드 환경과의 결합을 통한 사용의 범용성 및 접근성 확보, $\mathrm{DSDV}$ 라우팅 알고리즘의 활용 그리고 거리 제약 조건의 개선, 끝으로 하드웨어와 소프트웨어 통합설계를 통한 시제품 제작 측면에서 기존의 관련 연구와 차별된다.

\section{III. 위치 정보 시스템의 구현}

\section{1. 시스템 구조}

그림 2 는 본 논문에서 제안하는 시스템의 전체적인 구조도 
이다. 그림 2 에서 사용자 위치 정보 노드는 본 시스템에서 구현한 하드웨어 디바이스를 지칭하는 것으로, 4 장에서 자세 히 논의된다. 각 사용자 위치 정보 노드에 FreeRTOS를 포 팅하고 $\mathrm{DSDV}$ 라우팅 알고리즘을 구현하여 자체적으로 네트 워크를 형성한다. 노드 간에 구축된 네트워크는 안드로이드 환경에서 이를 확인할 수 있도록 구현된다.

표 1. DV 라우팅 테이블

Table 1. DV Routing Table

\begin{tabular}{|c|c|c||}
\hline Destination & Next Hop & Hop Count (distance) \\
\hline \hline A & A & 0 \\
$\ldots$ & $\ldots$ & $\ldots$ \\
C & E & 2 \\
D & E & 3 \\
\hline
\end{tabular}

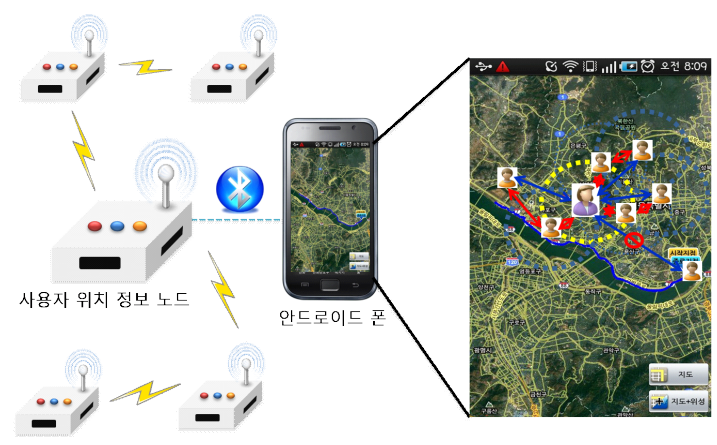

그림 2. 시스템 구조

Fig. 2. System Structure

\section{DSDV 알고리즘을 이용한 위치 정보 시스템}

DSDV(Destination Sequenced Distance Vector) 알 고리즘은 DV(Distance Vector) 알고리즘의 문제점을 해결 하는데, 우선 DV 알고리즘의 특징을 살펴보면 다음과 같다. $\mathrm{DV}$ 알고리즘에서의 모든 노드들은 라우팅 테이블을 유지하 면서, 주기적으로 라우팅 테이블을 모든 이웃들에게 전송한 다. 이 때, 홉 수가 Cost가 되어 홉 수가 최소인 최적의 경로 를 찾는다. 라우팅 테이블에서 Destination은 도착 가능한 모든 목적지이며, Nexthop은 목적지에 최적으로 도착하기 위해 거쳐 가야하는 노드이고, Hopcount는 목적지까지의 홉 수이다. 이상과 같은 $\mathrm{DV}$ 라우팅 테이블에 대한 예제가 표 1 에 소개되어 있다. 하지만 DV 알고리즘은 그림 3에서 보는 것처럼 루프 또는 무한 카운팅을 발생시킬 수 있다는 문제점 을 가지고 있다.

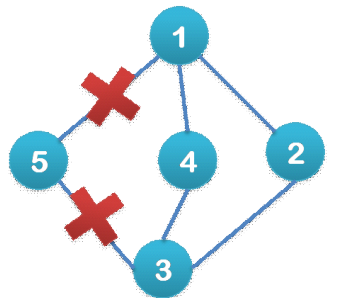

(1) 루프 발생

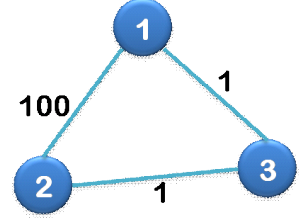

(2) 무한 카운팅 발생
그림 3. DV 알고리즘의 문제점

Fig. 3. The Problem of DV Algorithm

$\mathrm{DSDV}$ 라우팅 알고리즘은 이와 같은 $\mathrm{DV}$ 알고리즘의 개선 된 버전으로 다음과 같은 특징을 가진다. 우선, 모든 노드들 은 라우팅 테이블을 유지하면서, 주기적으로 라우팅 테이블을 모든 이웃들에게 전송한다. 이 때, 순서 번호를 이용하여 루 프가 발생하는 것을 방지하며, 각 노드들은 더 큰 순서 번호 의 정보로 갱신된다[8].

만약, 특정 노드가 네트워크상에서 연결이 끊어지면 Metric (Number of Hops to Destination)을 무한대로 설정하고, 순서 번호를 증가시킨 후 주위 노드들에게 정보를 송신한다. 주 위 노드들에게 보내는 라우팅 정보는 Destination, Metric, Destination Sequence Number이다[9]. 순서 번호는 각각 의 라우팅 정보 전송 시 자신의 순서 번호를 증가시키고, 만약 노드가 최종 목적지에 도달할 수 없다면 순서 번호를 1 증가시키 고 Metric을 무한대로 한다. 라우터 정보는 높은 목적지의 순서 번호가 도달하면 이를 갱신하며, 같은 순서 번호가 온다면 더 작은 Metric을 선택 한다. 마지막으로 새로운 노드가 추가되거 나 연결이 끊어질 경우 Metric의 변화는 즉시 이웃들에게 전파 된다. 표 2는 이와 같이 동작하는 $\mathrm{DSDV}$ 라우팅 알고리즘에서 사용하는 라우팅 테이블의 예제이다.

표 2. DSDV 라우팅 테이블

Table 2. DSDV Routing Table

\begin{tabular}{||c|c|c|c|c||}
\hline Dest & Next & Metric & Sequence No. & Install Time \\
\hline \hline A & A & 0 & A-550 & 1000 \\
$\ldots$ & $\ldots$ & $\ldots$ & $\ldots$ & $\ldots$ \\
C & B & 2 & D-588 & 1200 \\
\hline D & B & 3 & D-312 & 1200 \\
\hline
\end{tabular}


표 3. 패킷 정의

Table 3. Packet Definition

\begin{tabular}{||c|c|c|c|c|c|c|c|c||}
\hline Felid & Start Code & Src ID & Next ID & Dest ID & Length & Type & Data & Check Sum \\
\hline Size & 5 byte & 1byte & 1 byte & 1 byte & 1 byte & 1 byte & Variable & 1 byte \\
\hline
\end{tabular}

\section{3. 패킷 정의}

다음으로 본 논문에서 제안하는 위치 정보 시스템이 사용 하는 패킷의 구조를 정의 한다. 사용자 위치 정보 노드가 데 이터를 송수신 하는 과정에서 사용되는 패킷의 구조는 표 3 과 같다.

먼저 첫 번째 필드로서 Start Code는 데이터 전송의 시작 을 알리는 패킷이며 해당 필드의 크기는 $5 \mathrm{byte}$ 로 구성되어 있다. 다음으로 $\mathrm{Src}$ ID와 Next ID, 그리고 Dest ID 필드는 각각 송신지의 $\mathrm{ID}$, 라우팅 테이블에서 목적지에 도달하기 위 해 거쳐 가는 다음 노드 ID, 목적지의 ID이며, 각각의 크기는 1byte이다. Length는 1byte이며 Data길이 + 1(Type)의 값을 가지게 된다. Type 필드는 GPS 정보, GPS 정보에 대 한 $\mathrm{ACK}$ 정보, 라우팅 패킷, 라우팅 경로 요청, 라우팅 경로 응답으로 총 다섯 개로 나뉜다. Data 패킷은 실제 사용할 Data 값을 갖고 있으며 Type에 따라 크기가 유동적이다. 끝 으로, Check Sum은 Length부터 Data까지의 합에 반전을 취한 값을 사용하며 크기는 $1 \mathrm{byte}$ 이다.

\section{4. 블루투스 통신}

안드로이드 환경에서 블루투스 통신을 수행할 때 먼저 설 정하는 부분은 AndroidManifest.xml 파일에서 퍼미션을 지정하는 부분이다. 이 때, BLUETOOTH ADMIN 퍼미션 을 설정 한 후에 BLUETOOTH 퍼미션을 지정하여야 정상 적으로 동작한다[10]. 다음으로 블루투스 UUID를 설정해 야 하며, 이때 해당 어플리케이션에 맞는 UUID를 설정 해주 어야 한다. 본 논문에서 제안한 시스템의 경우는 $\mathrm{SSP}$ (Serial Port Profile)를 이용한다. 따라서 이에 맞는 UUID인 “00001101 - 0000 - 1000 - 8000 - 00805F9B34FB”를 사용한다.

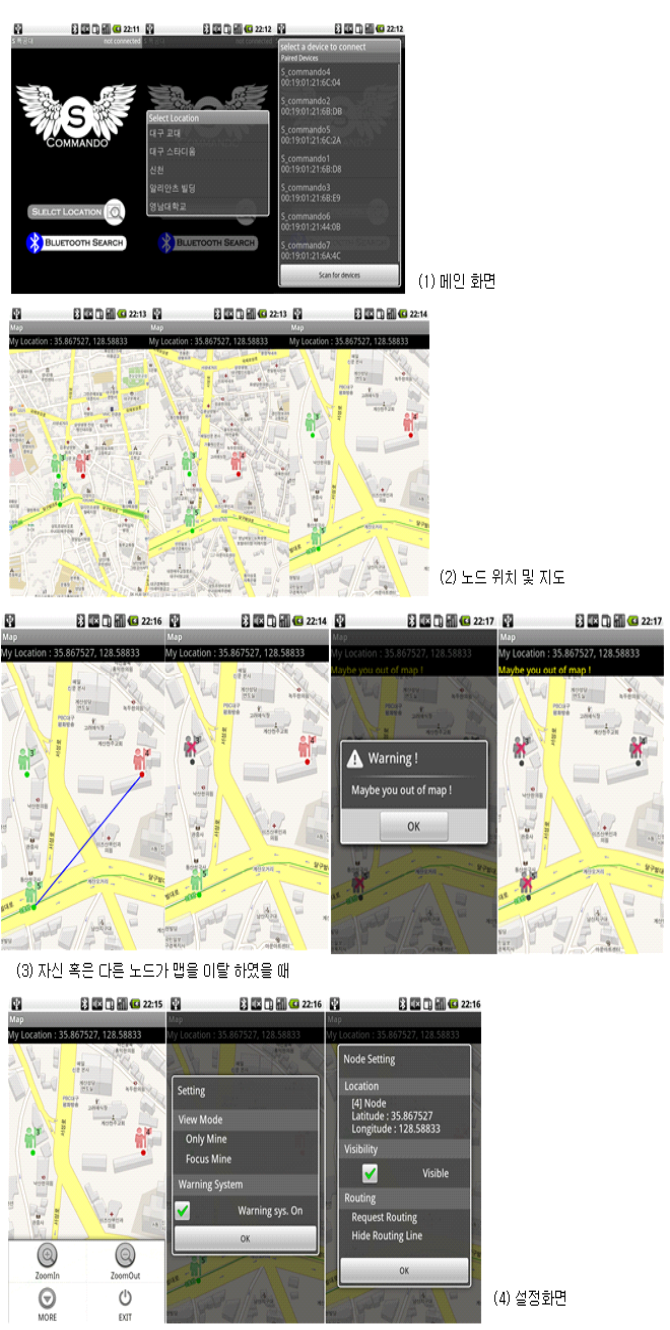

그림 4. 안드로이드 기반 시스템에서의 사용자 인터페이스

Fig. 4. User Interface in Android based System

\section{5. 안드로이드 어플리케이션}

안드로이드 사용자 인터페이스는 그림 4 에 나타나 있다. 메인 화면에 을 통해 실시간으로 노드의 위치를 확인할 수 있 으며, 노드가 기 구축된 네트워크상에서 이탈될 경우 안드로 이드 단말기에서는 이를 알려주는 이벤트가 발생한다. 만약 
자신의 노드가 네트워크를 이탈했을 경우 대화상자 (dialogue)로 알릴 수 있게 구현하였다[11][12].

\section{IV. 사용자 맵핑 시스템의 설계}

\section{1. 사용자 맵핑 시스템 구조}

이 절에서는 위치 정보 시스템과 상호 동작하게 되는 하드 웨어 장비로서, 사용자 맵핑 시스템의 전체적인 설계에 대해 논의한다. 우선, 그림 5 는 본 논문에서 제안하는 사용자 맵핑 시스템의 전체적인 구조이다. 먼저 사용자 위치 정보 노드 (u_LIN, User Location Information Node, 이하 $\mathrm{u} \_\mathrm{LIN}$ )란 본 연구를 통해 제작한 하드웨어 디바이스를 지칭 하는 것이며, 이하 이를 u_LIN이라 명명한다.

각 사용자 위치 정보 노드는 $\mathrm{ARM}$ 계열의 Cortex-M3 Chip을 사용하고 freeRTOS를 포팅 하였다. 또한 DSDV 라 우팅 알고리즘을 구현하여 자체적으로 네트워크가 형성된다 [8]. 그리고 사용자 위치 정보 노드 간에 구축된 네트워크는 안드로이드 환경과 블루투스 통신을 통해서 상호간 정보를 확 인할 수 있으며, 안드로이드 환경이 아닌 경우는 $\mathrm{LED}$ 를 통해 통신 정보를 나타낼 수 있도록 구현하였다.

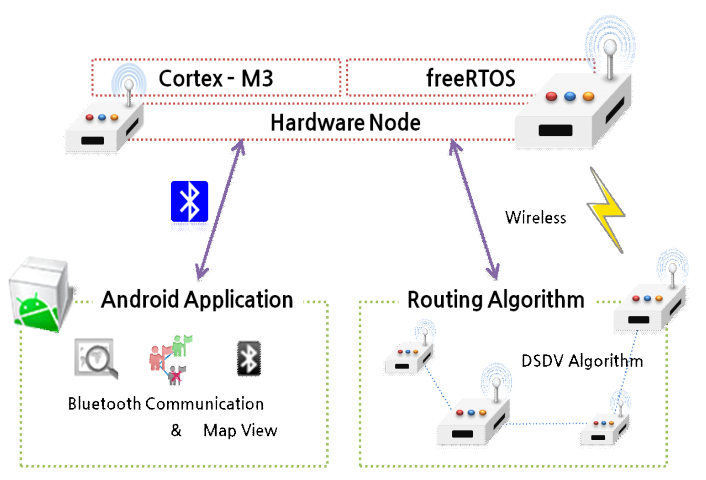

그림 5. 사용자 맵핑 시스템 구조

Fig. 5. User Mapping System Structure

\section{2. 사용자 맵핑 시스템 노드 구현}

사용자 위치 정보 노드 $(u$ LIN)는 다음과 같은 하드웨어 모듈로 구성되며, 내부의 세부적인 구성 요소는 그림 6 을 바 탕으로 다음과 같다.

먼저, 메인 프로세서인 $\mathrm{MCU}$ 는 $\mathrm{ARM}$ Core인
Cortex-M3 Architecture가 적용된 Micro-controller 중 의 하나인 STM32F103VBT6 Chip을 사용하였다. 외부/내 부 $8 \mathrm{MHz}$ 의 Crystal을 사용하며, 내부 PLL 회로를 통해 $72 \mathrm{MHz}$ 까지 클록을 사용할 수 있다. 그리고 이 같은 $\mathrm{MCU}$ 에 freeRTOS를 포팅 하였다.

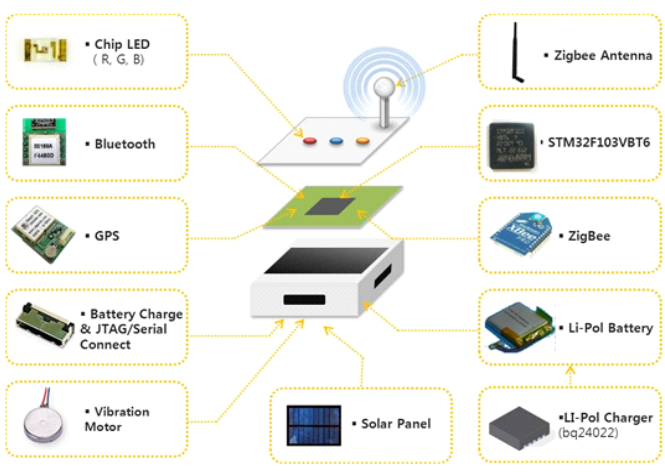

그림 6. uLLIN 시스템 구조

Fig. 6. u-LIN System Structure

두 번째로, 무선 통신은 지그비(Zigbee)와 블루투스를 활 용하는데, 지그비는 Xbee Pro U.FL 안테나 타입으로 각 노 드 간 네트워크를 형성하기 위한 통신 모듈이고, 블루투스는 안드로이드 폰에게 GPS 좌표와 같은 정보를 주기 위한 통신 모듈로 Cortex에서 생성된 GPS 좌표와 라우팅 데이터를 안 드로이드 환경에 전송한다[2].

세 번째로, 각 노드들은 자신의 GPS 데이터를 가지고 있 고, 다른 노드들 간의 네트워크 형성을 위해 각자의 위치 정 보를 주고 받는다.

네 번째로, Solar Panel은 구축된 네트워크에서 이탈하여 혼자 떨어지게 될 경우 배터리가 모두 소모되어 전력 공급이 힘든 상황을 위해, 긴급 시 태양 전지를 이용해 충전이 가능 하도록 설계하였다. 설계된 장비의 특성 상, 배터리 소모 시 에도 정상적인 동작을 보장토록 하기 위함이다.

다섯째, 본 논문에서 설계된 장비의 배터리 충전은 휴대폰 케이블을 이용하는 방법과 태양 전지를 이용하는 방법으로 두 가지를 제공한다. 어떤 방법으로 충전할지는 스위치를 통해 선택할 수 있도록 하였다.

마지막으로, 경고 및 알람은 네트워크 형성 후 하나 이상 의 노드가 네트워크에서 벗어날 경우 진동 모터를 이용해서 알람을 울려 경고를 하고, $\mathrm{LED}$ 를 통해 블루투스와 지그비, GPS 통신 상태를 알 수 있다. 


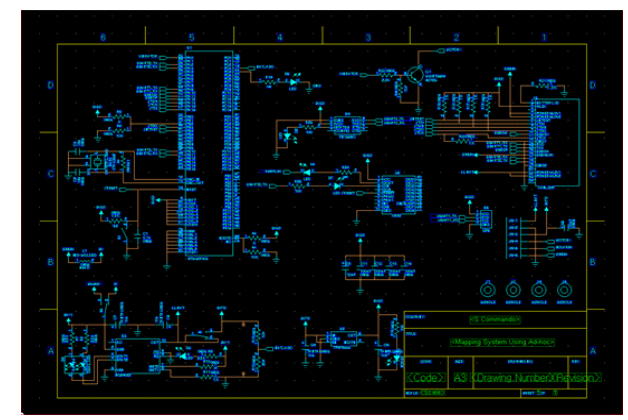

그림 7. 회로 설계

Fig. 7. Circuit Design

\section{PCB Artwork 및 프로토타입 시스템}

이상을 바탕으로, 그림 7에 $\mathrm{PCB}$ 기판 인쇄용 회로 설계도 가 소개되어 있다[13]. 이와 같이 주어진 회로를 $\mathrm{PADS}$ 2007 환경에서 Artwork을 수행하였을 때의 결과는 그림 8 에 소개되어 있다. 그림 8 (a)는 PCB 레이아웃 출력 결과이 며, 그림 8 (b)는 이를 바탕으로 제작된 실제 $\mathrm{PCB}$ 기판의 프 로토타입 모습이다.

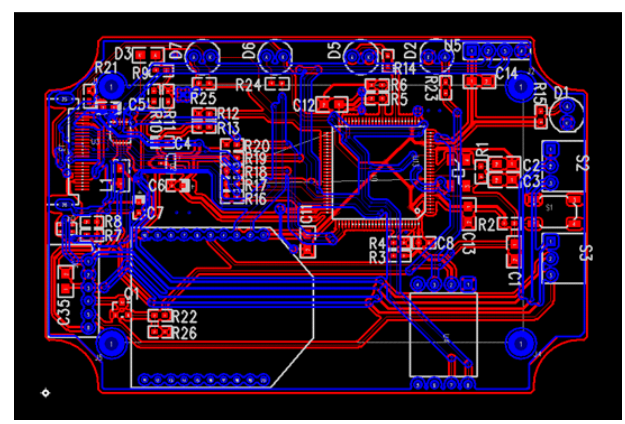

(a) PCB 레이아웃

(a) PCB Layout

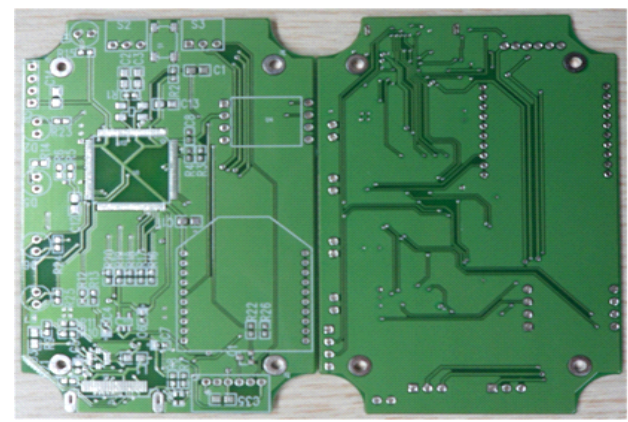

(b) PCB 기판 프로토타입

(b) PCB Prototype

그림 8. $\mathrm{PCB}$ 레이아웃 및 $\mathrm{PCB}$ 기판 프로토타입 Fig. 8. PCB Layout and Prototype PCB
끝으로, 그림 8의 완성된 $\mathrm{PCB}$ 기판에 플라스틱 외부 케이 스 및 사용자 입출력 환경을 완성한 최종 하드웨어 장비가 그 림 9에 나타나 있다. 앞면에는 비상시에 충전이 가능하도록 Solar Panel을 장착하였고, 상단부에는 안테나와 전원 스위 치, 충전 모드 스위치로 구성하였다. 옆면은 상태 확인을 위 한 LED이다. 맨 위에 위치한 LED는 GPS 상태를 나타내고, 두 번째 $\mathrm{LED}$ 는 블루투스 상태를 나타낸다. 세 번째 LED는 $\mathrm{TX}$ (송신) 상태, 마지막 LED는 $\mathrm{RX}$ (수신) 상태를 나타낸다.

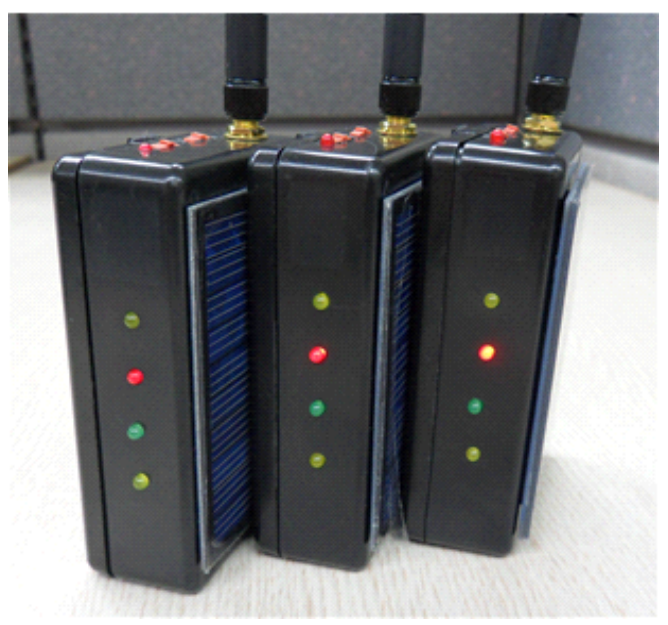

그림 9. 완성된 $u$ LIN 시스템 Fig. 9. u-LIN System

\section{V. 성능 평가}

이절에서는 이상에서 소개된 소프트웨어 기반 위치 정보 시스템과 하드에어 기반 사용자 맵핑 시스템의 동작 정확성 및 성능에 대해 논의한다. 우선, 소프트웨어 및 하드웨어 시 스템 개발 환경에 대해 소개하며, 다음으로 $1: 1$ 통신 및 $1: \mathrm{N}$ 통신의 실험 결과에 대해 노드 개수, 노드간 거리 및 네트워 크 타입 측면에서 논의한다.

\section{1. 개발 환경}

본 논문에서 구현한 시스템의 개발 환경은 다음과 같다. 우선, Operating System은 Windows XP SP3과 Windows 7을 사용하였다. 주요 개발 툴은 Inventor 2008, PADS2007, Orcad10.5, IAR Embedded Workbench 5.41, Android SDK 2.1v, Eclipse Galileo를 사용하였다. 개발 언어는 사용자 위치 정보 노드에서 $\mathrm{C}$ 를 사용하였고, 안 드로이드 어플리케이션은 JDK 1.6 을 사용하여 구현하였다. 


\section{2. 실험 결과}

\section{1 사용자 위치 정보 노드 간 1:1 통신}

본 논문에서 구현한 시스템으로 두 대의 사용자 위치 정보 노드 간 $1: 1$ 통신을 직선거리에서 수행한 결과는 다음과 같 다. 우선, 표 4에 나와 있는 것처럼 제안된 시스템은 최대 거 리 약 $250 \mathrm{~m}$ 까지 정상적으로 동작하는 것을 확인하였다. 전 체적으로는 중간에 하나 이상의 노드가 사라질 경우, 진동이 나 알람으로 경고 시스템을 활성화하며, 이 경우도 직선으로 최대 거리 $250 \mathrm{~m}$ 안에 노드가 있는 경우 전체적인 통신이 끊 어지지 않고 데이터를 주고받는 것을 확인하였다.

\section{2 사용자 위치 정보 노드 간 $1: \mathrm{N}$ 통신}

다음으로 본 논문에서는 $1: 1$ 통신을 확장하여 사용자 위 치 정보 노드 간 $1: \mathrm{N}$ 통신을 수행하였다. 이는 본 논문이 구 현한 시스템으로 하나의 사용자 위치 정보 노드가 N개의 서 로 다른 노드와 통신을 통해 데이터를 원활히 주고받을 수 있 는 지를 확인하기 위함이다. 실험 결과는 표 4 에 소개되어 있 으며, 결과 분석은 다음과 같다.

먼저, 사용자 위치 정보 노드 간 약 $100 \mathrm{~m}$ 이내의 거리에 서 직선으로 3개의 사용자 위치 정보 노드로 통신을 수행 한 결과 정상적으로 데이터가 송·수신 되는 것을 확인하였다. 다 음으로, 약 $100 \mathrm{~m}$ 이내의 거리에서 삼각형 형태로 3 개의 사 용자 위치 정보 노드로 통신을 수행한 결과 정상적으로 데이 터를 주고받는 것을 확인하였다. 세 번째로, 노드 간 약 $75 \mathrm{~m}$ 이내의 거리에서 4 개의 노드로 ' $\mathrm{T}$ ' 형태의 망을 통한 통신 결 과 역시 정상적으로 데이터를 주고받는 것을 확인하였으며, 마지막으로 노드 간 약 $50 \mathrm{~m}$ 이내의 거리에서 6 개의 노드로 통신한 결과, 노드들이 정상적으로 데이터를 송.수신하는 것 을 확인하였다.

표 4. 성능 평가 결과 Table 4. Experimental Results

\begin{tabular}{|c|c|c|c|}
\hline \multirow{2}{*}{$1: 1$} & 노드 개수 & $\begin{array}{l}\text { 정상동작 } \\
\text { 최대거리 }\end{array}$ & 비고 \\
\hline & 2개 & $250 m$ & 직선 \\
\hline \multirow{5}{*}{$1: \mathrm{N}$} & 노드 개수 & 노드 간 거리 & 비고 \\
\hline & 3개 & $100 \mathrm{~m}$ & 직선 \\
\hline & 3개 & $100 m$ & 삼각형 \\
\hline & 4개 & $75 m$ & T 형 \\
\hline & 6개 & $50 \mathrm{~m}$ & 육각형 \\
\hline
\end{tabular}

전체적으로는 중간에 하나 이상의 노드가 사라질 경우 진 동으로 경고하며 이 경우도 직선으로 최대 거리 $250 \mathrm{~m}$ 안에 노드가 있는 경우 전체적인 통신이 끊어지지 않고 데이터를 송.수신 하는 것을 확인하였다. 이와 같은 결과를 기존 관련 연구와 비교 분석해 보면 다음과 같다. 우선, 실내에서 $\mathrm{Wi}-\mathrm{Fi}$ 를 이용한 설계 방식과의 비교에서는 두 기법 모두 최근 들어 급속히 대중화 되고 있는 안드로이드 환경에서의 구현이라는 공통점이 있지만, 본 연구에서는 기존 실내에서만 동작하는 위치 정보 시스템의 제약 조건을 해소 하였다[6]. 또한 단말 기의 동작 거리 측면에서도 기존 연구 대비 약 $100 \mathrm{~m}$ 가량 정 상 동작 최대 거리를 향상시켰다[7].

\section{VI. 결론}

본 논문은 소수의 관리자가 이동성을 가지는 다수의 관리 대상들을 관리할 때, 효율적인 관리를 가능하게 하고 또한 예 측하지 못한 돌발 상황을 대비하기 위한 시스템으로 DSDV 라 우팅 알고리즘을 이용한 위치 정보 시스템과 Ad-hoc 네트워크 를 이용한 사용자 맵핑 시스템을 설계하고 이를 구현하였다.

본 논문에서 구현한 위치 정보 시스템은 단말 장치 사이에 서로 데이터를 송·수신하며, 상호 위치를 파악하여 독립적인 네트워크를 구성한다. 또한 본 논문에서 하드웨어적으로 구현 하여 명명된 u_LIN 디바이스는 노드 상호간의 통신을 통해 서로의 위치를 파악하여 독립적인 네트워크를 구성한다. 만약 하나 이상의 사용자 위치 정보 노드가 기 구축된 네트워크에 서 사라질 경우 진동 혹은 알람 등으로 상황을 알린다. 또한 안드로이드 환경을 지원하는 단말기와의 블루투스 통신을 통 해 실시간으로 노드의 위치를 확인할 수 있게 하였으며, 사용 자 정보 노드가 네트워크에서 이탈될 경우 안드로이드 단말에 서도 이를 확인할 수 있도록 구현하였다.

본 논문에서 제안된 시스템의 성능을 평가한 결과, $1: 1$ 통 신은 최대 $250 \mathrm{~m}$ 직선거리에서 통신이 가능하며, $1: \mathrm{N}$ 통신 및 다양한 형태의 노드 구성에 있어서도 정상적으로 데이터를 송-수신하는 것이 가능하였다. 이는 관련 연구 대비 거리 제 약 조건을 대폭 완화시킨 결과이다. 본 논문에서 제안된 시스 템은 $\mathrm{Ad}-\mathrm{hoc}$ 네트워크의 특징에 기반을 두어 독립적인 네트 워크를 구성한다. 따라서 $3 \mathrm{G} / 4 \mathrm{G}$ 혹은 $\mathrm{Wi}-\mathrm{Fi}$ 와는 다른 독립 적인 네트워크를 구성하기 때문에, 유치원 아동 관리 시스템, 놀이공원 미아 방지 시스템, 관광 가이드의 관광객 관리 시스 템 등 여러 시스템에 유연하게 적용 가능하므로 활용 방안이 
다양할 것으로 예상된다.

\section{참고문헌}

[1] William Stalling, "Data and Computer Communications", 10th edition, 2013

[2] B. A. Forouzan, "Data Communications and Networking”, McGraw-Hill, 2013

[3] Thomas Kunz, S. S. Ravi, "Ad-hoc, Mobile, And Wireless Networks", Springer-Verlag New York Inc, 2006

[4] David Coudert, Ad-Hoc, Mobile and Wireless Networks, Springer, 2012

[5] Frikha, Mounir, "Ad Hoc Networks : Routing, QoS and Optimization", Wiley-Iste, January 2011

[6] O. Kwon et al., "Design and Implementation of Location Information System using Indoor Wi-Fi", The journal of digital policy \& management, Vol. 11, No. 4, April, 2013

[7] H. Kwak et al., "Design and Implementation of Pedestrian Position Information System in GPS-disabled Area", Journal of academiandustrial technology, Vol. 13, No. 9, September, 2012

[8] C. E. Perkins and P. Bhagwat, "Highly Dynamic Destination-Sequenced Distance-Vector Routing F(DSDV) for Mobile Computers," Proc. of ACMSIGCOMM, 1994

[9] Maddipour, E, Rahman A.M. and Aminian E, "Performance Evaluation of Destination-equenced Distance-Vector (DSDV) Routing Protocol", 2009 international conference on future networks, pp 186-190, 2009

[10] http://developer.android.com/resources/samples/ BluetoothChat/ index.html

〔11] Frank Ableson, Charlie Collins, Robi Sen, "Unlocking Android - A developer's guide", Manning, 2010

[12] D. Torres Milano, "Android Application Testing Guide", PACKT, 2012

〔13] Mitzner, Kraig, "Complete PCB Design Using
OrCAD Capture and PCB Editor", Newnes, 2009

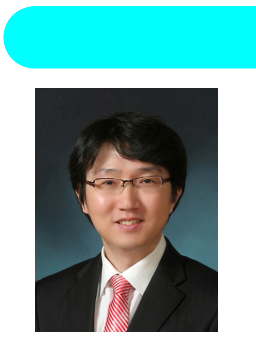

\section{저 자 소 개}

\section{곽 종 욱}

1998: 경북대학교

컴퓨터공학과 공학사.

2002: 서울대학교

컴퓨터공학과 공학석사.

2006: 서울대학교

전기컴퓨터공학부 공학박사

현 재: 영남대학교

컴퓨터공학과 부교수

관심분야: 컴퓨터 구조,

고성능 컴퓨팅,

임베디드 시스템

Email : kwak@yu.ac.kr 